СПИСАНИЕ НА БЪЛГАРСКОТО ГЕОЛОГИЧЕСКО ДРУЖЕСТВО, год. 82, кн. 3, 2021, с. 159-161

REVIEW OF THE BULGARIAN GEOLOGICAL SOCIETY, vol. 82, part 3, 2021, p. 159-161

\title{
Use of two contemporary remote sensing technologies for mapping the Thracian Cliffs landslide (Northern Bulgarian Black Sea Coast)
}

\section{Два сьвременни метода за картографиране на свлачище „Тракийски скали“" чрез дистанционни изследвания (Северно Черноморие на България)}

\author{
Mila Atanasova ${ }^{1}$, Hristo Nikolov ${ }^{2}$ \\ Мила Атанасова ${ }^{1}$ Христо Николов ${ }^{2}$ \\ ${ }^{1}$ National Institute of Geophysics, Geodesy and Geography, Bulgarian Academy of Sciences, 1113 Sofia; \\ E-mail: mila_at_zl@abv.bg, \\ ${ }^{2}$ Space Research and Technology Institute, Bulgarian Academy of Sciences, 1113 Sofia; E-mail: hristo@stil.bas.bg
}

\begin{abstract}
In this paper are presented the results from the investigations of the active landslide, located in front of the Thracian Cliffs golf club (Northern Bulgarian Black Sea Coast) for the period 2019-2021. Extensive research by means of in-situ and remote sensing has been carried out on the latest landslide activations. As part of the study, a control GNSS geodynamic network was established. This network was used as benchmark for the results obtained from satellite SAR data processing and UAV surveys targeted at monitoring the modern landslide developments.
\end{abstract}

Keywords: landslides, UAS technology, GNSS RTK data, InSAR.

\section{Въведение}

Районът на изследване на настоящото проучване е активното свлачище (DOB17.05009-01-03), разположено в близост до с. Топола. То се развива по крайбрежния склон, непосредствено пред входа на голф клуб „Тракийски скали“ (фиг. 1а) (Geozashtita Varna Ltd., 2019). Комбинирането на данни от високоточни GNSS (Глобални навигационни спътникови системи), въздушна фотограметрия с безпилотни летателни апарати (БЛА) и InSAR (Радарна интерферометрия със синтезирана апертура) за наблюдение на свлачища в Северното Черноморие на България, извършени през последните 3 години, имат за цел да допринесат за подпомагане на геодезичните и геоложки изследвания (Nankin, Ivanov, 2019; Atanasova, Nikolov, 2020; Nankin et al., 2020; Ivanov et al., 2020). Тази комбинация от GNSS и свободно достъпни данни InSAR са успешно използвани за откриване и наблюдение на деформации на земната повърхност с широко пространствено покритие и поради високата си точност, която те предлагат, са много подходящи за изследване на тектонски или геодинамични процеси.

За да се оцени опасността от свлачищни процеси, данните от дистанционни изследвания от въздушни и сателитни инструменти се използват широко за наблюдение на движенията на земната повърхност през фиксирани интервали. Тези методи са по-евтини и отнемат по-малко време от геодезичните теренни измервания, а и от друга страна размерът на изследваните площи е по-голям. Това бяха причините за започване на проучвания на повърхностните деформации в района на свлачище „Тракийски скали“ чрез дистанционни методи. В конкретното изследване бяха използвани два източника на данни за създаване на карта в споменатата област - фотограметрични проучвания с БЛА за картиране на свлачището и сателитни изображения от радар със синтезирана апертура за последяване на премествания на повърхността. Данните от SAR се предоставят безплатно от ESA от мисията Sentinel-1, която включва два сателита. Об- 
работката на тези данни беше извършена чрез DInSAR метод за интерферометрична обработка, внедрен в софтуера SNAP. Изготвени са карти на свлачищната зона, изобразяваща регистрираните измествания на земята.

\section{БЛА технология}

Цифровата фотограметрия е техника, която позволява топографията да бъде реконструирана като 3D модел, като по този начин предоставя 3D пространствена информация от характеристики и елементи, видими в две или повече изображения (Lindner et al., 2016; Devoto et al., 2020). Изображенията от БЛА са геоориентирани и калибрирани с помощта на наземните контролни точки (GCP), измерени с RTK GNSS с точност до $1 \mathrm{~cm}$, което позволява да се получат облаци от точки с висока разделителна способност, заедно с цифрови повърхностни модели (DSM), ортофото и точно 3D представяне на обекти или повърхности. Характеристиките на използвания БЛА и следващата фотограметрична обработка на всички изображения, извършена от софтуера Pix4Dmapper (Pix4D, 2020), позволиха достигане на пространствена разделителна способност на цифрови продукти $5 \mathrm{~cm}$. Авторите изразяват своята благодарност към фирма „GEO+“ за реализирането на това проучване чрез БЛА (фиг. 1a, б) през ноември 2020. Планира се да се извърши ново проучване с БЛА на изследваната зона в края на есента на 2021 г., за да може да се проследят едногодишните повърхностните движения.

\section{GNSS данни}

Геодезичните GNSS мрежи, използвани за наблюдение на свлачища, се състоят най-общо от два типа точки: контролни - фиксирани точки, разположени на геоложки стабилен терен и точки за проучване, разположени в рамките на свлачището. В нашето проучване данните от стабилни точки, разположени в недеформируема зона, бяха използвани GNSS данни от 4 непрекъснато работещи референтни станции от националната GNSS мрежа, подържана от НИГГГ-БАН. Точките на новосъздадената геодинамична мрежа се намират вътре в изследваното свлачище и са измерени в 3 цикъла (19-23 юни 2019 г., 22-27 юли 2020 г. и третият през 21-28 юни 2021 г. данните се обработват в момента). В нея са включени 10 стабилизирани точки, които се използват за наблюдение на деформациите по пътя, водещ до голф клуба и точки, разположени в скалите и пьтеката, свързваща плажа с курорта Topola Skies (фиг. 1в).

\section{InSAR технологии}

SAR технологиите са изключително подходящ инструмент за наблюдение на земната повърхност. SAR системите са в състояние да генерират триизмерни изображения на наблюдаваните
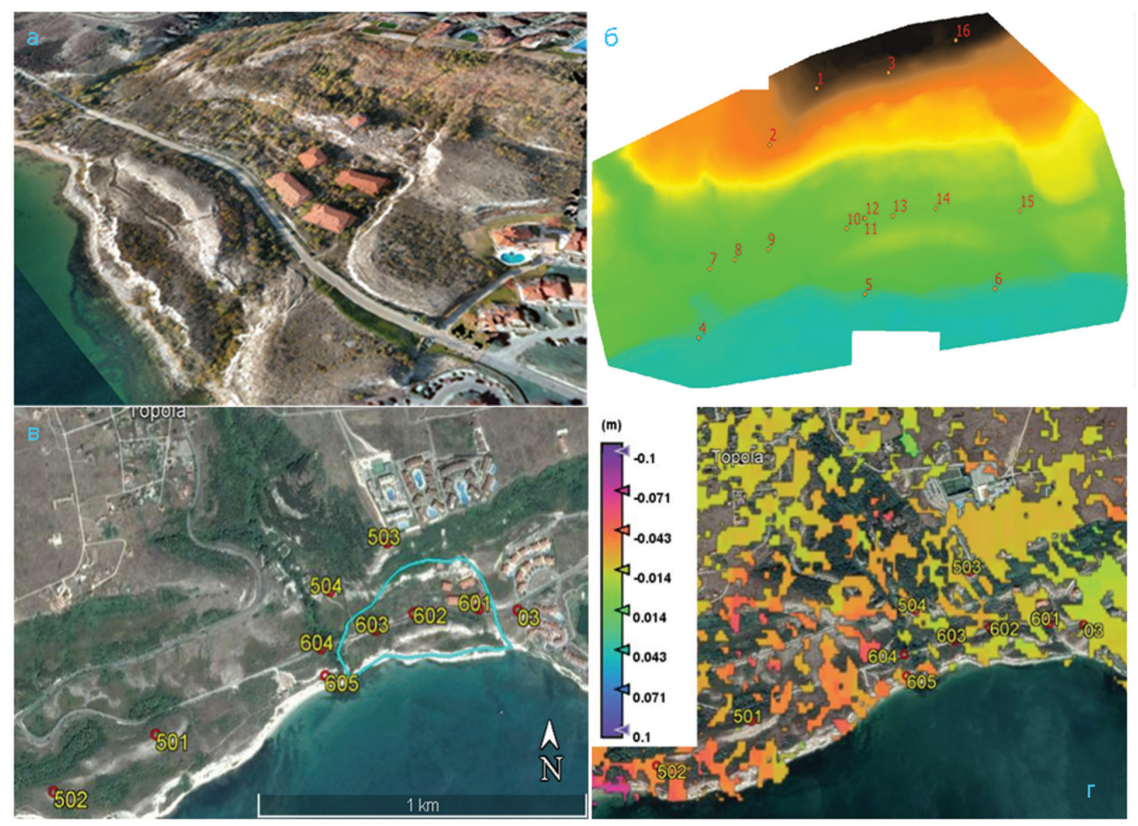

Фиг. 1. а) Свлачище пред голф клуб „Тракийски скали“, заснето с БЛС на 27.11.2020 г.; б) генериран DSM във формат GeoTIFF и контролни точки (GCP) измерени с RTK GNSS; в) локална ГНСС мрежа; г) регистрирани земни премествания от InSAR в изследваната зона за периода 15.11.2017-27.03.2018 г. 
обекти, като в тях се включва информацията за амплитудата или фазата на отразения сигнал. Технологията InSAR е метод, който създава ново разликово изображение от две SAR изображения, регистрирани в различни моменти от време за един и същи район от земната повърхност. Основният метод за обработка и създаване на изображения e DInSAR метод, при който от фазовия сигнал се елиминира ефекта на релефа с помощта на външен цифров модел на терена (DEM). Така се достига до изображение, което съдържа само промените, настьпили на повърхността между двете регистрации. Важен етап от обработката е разгъването на интерферометричната фаза, след който тя бива геокодирана в конвенционална геодезическа система и тогава може да се изработи карта на повърхностните движения. Самото интерферометричното изображение представлява цветно изображение на фазовия сигнал, в което не е видима промяна в цвета, ако не са регистрирани деформации по повърхността или се наблюдава ефектът „сол и пипер“, в случай че кохерентността за конкретен район е твърде ниска (Ferretti et al., 2007; Braun, Veci, 2021).

За да се повиши надеждността на информацията, получена от данните за SAR, беше създаден локален архив от SLC изображения от S-1 от началото на 2015 г. до момента, като в него са включени данни от възходящи и низходящи орбити. В Atanasova \& Nikolov (2020) са показани извадки от множеството произведени интерферограми във времевите серии 2015-2021 г. по Северното Черноморие на България. На фиг. 1г е изобразена една от множеството генерирани карти на преместванията, базирана на интерферометрични изображения от SAR данни за различни периоди. Цветьт на пикселите представлява движението на повърхността в размер на метър за изследвания период, вариращо от тъмносиньо до лилаво. Особено уязвимите зони са показани в тьмносиньо и лилаво, а по-малко уязвимите - в жълто и зелено. На същата фигура са показани преместванията на земната повърхност по визираната линия на радара (LOS), които са в интервала между 8-10 cm.

\section{Заключение}

Прилагането на съвременни технологии за наблюдение значително улеснява мониторинга на процесите на деформиране на свлачища. Получените резултати от съвместно използване на GNSS и InSAR за мониторинг на свлачища в Ceверното Черноморие на България показват висока надеждност. При сравнение между различните методи за мониторинг със сигурност е трудно да се избере само един подход, но комбинация- та от прецизни измервания на GNSS, допълнени от свободно достъпни SAR данни и резултати от фотограметрично заснемане от БЛА, в значителна степен подобряват крайния резултат. Проведените изследвания демонстрират потенциала и възможностите на времеви редове от сателитни SAR данни за изследване и наблюдение деформациите на земната повърхност, както и да измерват техните вариации по LOS със сантиметрова точност във времето. Трябва да се подчертае, че повърхностните деформации, получени от сателитни данни, изискват прецизни изчисления и допълват теренните измервания и биха могли да ги насочат, но не и да ги заменят. Друго предимство на метода DInSAR е, че позволява получаване на информация за поведението на големи площи, без да е необходимо скъпо оборудване и човешки усилия.

Благодарности: Тези изследвания са реализирани с финансовата подкрепа на Националния Фонд за научени изследвания, проект КП-06ОПР $06 / 1$ от 14.12 .2018 г.

\section{Литература \\ References}

Atanasova, M., H. Nikolov. 2020. Integrative use of GNSS and InSAR data: a case study of landslide on the Thracian rocks coastal slope. - In: Proc. SPIE 11534, Earth Resources and Environmental RS/GIS Applications XI, 115340S; https:// doi.org/10.1117/12.2573641.

Braun, A., L. Veci. 2021. TOPS Interferometry Tutorial. SkyWatch Space Applications Inc., Updated 2021, 25 p.; https:// step.esa.int/docs/tutorials/S1TBX\%20TOPSAR\%20Interferometry\%20with\%20Sentinel-1\%20Tutorial_v2.pdf.

Devoto, Q. S., V. Macovaz, M. Mantovani, M. Soldati, S. Furlani. 2020. Advantages of using UAV digital photogrammetry in the study of slow-moving coastal landslides. Remote Sens., 12, 21, 3566; https://doi.org/10.3390/rs12 213566.

Ferretti, A., A. Monti-Guarnieri, C. Prati, F. Rocca, D. Massonnet. 2007. InSAR Principles: Guidelines for SAR Interferometry Processing and Interpretation. ESA Publications, TM-19.

Geozashtita Varna Ltd. 2019. Annual Report. 207 p.

Ivanov, P., R. Nankin, V. Zaalishvili. 2020. Assessment of landslide susceptibility and hazard along the northern Bulgarian Black Sea coast. - Proc. 1st International Conference on Environmental Protection and disaster RISKs, Part 2, 392-404.

Nankin, R., P. Ivanov. 2019. Current state of the landslides affecting the Northern Bulgarian Black Sea Coast. - Rev. Bulg. Geol. Soc., 80, 3, 176-178 (in Bulgarian with English abstract).

Nankin, R., P. Ivanov, M. Krastanov. 2020. Thracian Cliffs landslide, Northern Bulgarian Black Sea Coast. - Rev. Bulg. Geol. Soc., 81, 3, 215-217 (in Bulgarian with English abstract).

Lindner, G., K. Schram, R. Mansberger, J. Hüb. 2016. UAV monitoring and documentation of a large landslide. - App. Geomatics, 8, 1-11; https://doi.org/10.1007/s12518-0150165-0.

Pix4D. 2020. Pix4D. Drone Mapping Software; https://pix4d. $\mathrm{com} /$. 